\title{
Propyl-Sulfonic Acid Functionalized Nanoparticles as Catalyst for Pretreatment of Corn Stover
}

\author{
Leidy Peña ${ }^{1}$, Feng Xü ${ }^{1}$, Keith L. Hohn ${ }^{2}$, Jun Li ${ }^{3}$, Donghai Wang ${ }^{{ }^{*}}$ \\ ${ }^{1}$ Department of Biological and Agricultural Engineering, Kansas State University, Manhattan, USA; ${ }^{2}$ Department of Chemical Engi- \\ neering, Kansas State University, Manhattan, USA; ${ }^{3}$ Department of Chemistry, Kansas State University, Manhattan, USA. \\ Email: $\underline{\text { dwang@ksu.edu }}$
}

Received November $15^{\text {th }}, 2013$; revised December $16^{\text {th }}, 2013$; accepted December $26^{\text {th }}, 2013$

Copyright (C) 2014 Leidy Peña et al. This is an open access article distributed under the Creative Commons Attribution License, which permits unrestricted use, distribution, and reproduction in any medium, provided the original work is properly cited. In accordance of the Creative Commons Attribution License all Copyrights @ 2014 are reserved for SCIRP and the owner of the intellectual property Leidy Peña et al. All Copyright (C) 2014 are guarded by law and by SCIRP as a guardian.

\section{ABSTRACT}

Propyl-sulfonic (PS) acid-functionalized nanoparticles were synthesized, characterized and evaluated as catalysts for pretreatment of corn stover. Silica coated nanoparticles were functionalized with $0.5 \%$ mercaptopropyltrimethoxysilane (MPTMS) at neutral pH in a mixture of water and ethanol. Sulfur contents of the acid functionalized nanoparticles, measured in a CHNS analyzer, varied from $6 \%-10 \%$, and the acid load ranged from 0.040 to $0.066 \mathrm{mmol} \mathrm{H}^{+} / \mathrm{g}$. A Box-Behnken design was employed to calculate the minimum number experiments required to obtain an estimate of the surface response for temperature, catalyst load, and \%S content of the catalyst. Pretreatment of corn stover was carried out at three temperature levels 160,180, and $200^{\circ} \mathrm{C}$ for $1 \mathrm{~h}$. Three levels of catalyst load were used $0.1,0.2$, and $0.3 \mathrm{~g}$ of catalyst per gram of biomass. Hydro-thermolysis controls were carried at each temperature level. The catalyst load did not have an effect on the glucose yield at $160^{\circ} \mathrm{C}$, and the average glucose yield obtained at this temperature was $59.0 \%$. The glucose yield was linearly correlated to the catalyst load during pretreatment at $180^{\circ} \mathrm{C}$, and a maximum glucose yield of $90 \%$ was reached when using $0.2 \mathrm{~g}$ of PS nanoparticles that had a total sulfur content of $6.1 \%$. Complete hydrolysis of glucose was reached at $200^{\circ} \mathrm{C}$ but the average xylose yield was $4.6 \%$, and about $20.2 \%$ of the combined glucose and xylose were lost as hydroxymethylfurfural and furfural. Results showed that acid-functionalized nanoparticles can be potential catalysts for the pretreatment of biomass for its later conversion to ethanol.

\section{KEYWORDS}

\section{Acid Functionalized Nanoparticles; Catalyst; Biomass Pretreatment; Hydrolysis}

\section{Introduction}

One of the challenges in the production of bioethanol and chemicals from lignocellulosic biomass is breaking down the complex structure of biomass into monomeric sugars. Biomass has a complex mixture of cellulose, hemicellulose, and lignin. A pretreatment step is required to make the biomass cellulose fraction more susceptible to enzymatic hydrolysis. It has been found that the removal of lignin and the consequent solubilization of hemicelluloses favor the enzymatic digestion of cellulose [1]. The most accepted method for pretreatment of lignocellulosic biomass uses corrosive catalysts such as hydrochloric

${ }^{*}$ Corresponding author. acid or sulfuric acid [2-6]. The need for corrosion resistant materials which require higher capital investment can be avoided when using less corrosive catalysts. Thermochemical pretreatment of biomass generates decomposition products such as hydroxymethylfurfural (HMF) and furfural. Pretreated biomass must be detoxified to remove these products because they could inhibit the microorganisms used during the sugar fermentation to ethanol [7]. Chemical pretreatment of lignocellulosic biomass incurs additional costs for disposal of residues from neutralization and biomass conditioning. Solid acids provide similar catalytic advantages as their liquid counterparts, with the additional benefit that solid acids can be recovered and reused [8-11]. Solid acids in the nanoscale pre- 
vent the mass transfer problems that common heterogeneous catalysts generate. Acid functionalized nanoparticles could be used to replace mineral acids during biomass pretreatment for cellulosic ethanol production. Silica-coated nanoparticles (SiMNPs) can be modified to confer them with desired chemical properties [12]. 3mercaptopropyltrimethoxysilane (MPTMS) is commonly used to graft sulfonic acid functional groups on silica materials. The acid functionalization of SiMNPs can be done using similar procedures to those reported on acid functionalization of silicas $[13,14]$. Acid functionalized silica materials have been used as catalyst of the $\alpha-1,4-$ glycosidic bonds in sucrose and starch [15] and $\beta$-1,4glycosidic bonds in cellobiose [16]. Acid functionalized nanoparticles were previously used for the hydrolysis of cellobiose [17] and for the solubilization of hemicelluloses [18]. In this work, silica coated cobalt iron oxide nanoparticles functionalized with propyl-sulfonic acid groups were synthesized and used as catalyst for the pretreatment of corn stover.

\section{Methods and Methods}

\subsection{Materials}

Cobalt (II) chloride hexahydrate (99\%), D-(+)-Cellobiose (98\%), iron (II) chloride tetrahydrate (99.99\%), MPTMS (95\%), methylamine (40\%w/w, 98.5\%), sodium dodecyl sulfate (98.5\%), and tetraethylorthosilicate (TEOS) (99.999\%) were purchased from Sigma-Aldrich (St. Louis, Mo., USA). Ammonium hydroxide, toluene, and isopropanol (A.C.S. reagent) were purchased from Fisher Scientific (Pittsburgh, Pa, USA). Ethanol (95\%) was purchased from Decon Laboratories (King of Prussia, Pa., USA). Corn stover was harvested from the Kansas State University Agronomy Farm in October 2011. Corn stover was ground in a cutting mill (SM2000, Retsch, Inc., Newtown, Pa.) to pass a $1 \mathrm{~mm}$ mesh. The chemical composition of corn stover is listed in Table 1.

\subsection{Synthesis of SiMNPs}

Cobalt iron oxide nanoparticles were synthesized by precipitating salts of $\mathrm{Co}^{2+}$ and $\mathrm{Fe}^{2+}$ using a microemulsion method $[19,20]$. In a typical experiment, a solution was prepared with $4 \mathrm{mmol}$ (0.9 g) of cobalt (II) chloride hexahydrate $\mathrm{CoCl}_{2} \cdot 6 \mathrm{H}_{2} \mathrm{O}, 10 \mathrm{mmol}$ (1.9 g) of iron (II) tetrahydrate $\mathrm{FeCl}_{2} \cdot 4 \mathrm{H}_{2} \mathrm{O}$, and $45 \mathrm{mmol}(12.9 \mathrm{~g})$ of sodium dodecyl sulfate (SDS). The salts and surfactant were dissolved in distilled water, mixed and diluted to $1 \mathrm{~L}$. One liter solution of $12 \mathrm{wt} \%$ methylamine was also prepared. After stirring the first solution for $30 \mathrm{~min}$ at room temperature, both solutions were heated to $55^{\circ} \mathrm{C}-65^{\circ} \mathrm{C}$ and then combined. The mixture was kept at $55^{\circ} \mathrm{C}-65^{\circ} \mathrm{C}$ under rigorous mechanical stirring. After three hours, the particles were magnetically separated and washed three
Table 1. Biomass composition (dry basis)*

\begin{tabular}{cc}
\hline Biomass constituents & Corn stover \\
\hline 95\% ethanol extractives & $21.8 \pm 3.8$ \\
Glucan (\%) & $30.2 \pm 2.6$ \\
Xylan (\%) & $18.4 \pm 2.3$ \\
Arabinan (\%) & $1.9 \pm 0.3$ \\
Acid-soluble lignin (\%) & $1.0 \pm 0.1$ \\
Acid-insoluble lignin (\%) & $14.5 \pm 0.4$ \\
Total lignin (\%) & $15.4 \pm 0.5$ \\
Acid-insoluble ash (\%) & $2.1 \pm 0.3$ \\
\hline
\end{tabular}

*The data presented are averages of three independent analyses.

times with water and once with ethanol. Then the particles were stored in $100 \mathrm{~mL}$ of ethanol.

Cobalt iron oxide nanoparticles were coated with silica using the procedures reported in the literature $[13,17,21]$. The dispersion of $\mathrm{CoFe}_{2} \mathrm{O}_{4}$ in ethanol was sonicated for 1 h. About $15 \mathrm{ml}$ of this solution were added to $550 \mathrm{ml}$ blend isopropanol and water 9:1. This solution was sonicated and mechanically stirred for $30 \mathrm{~min}$. One $\mathrm{mL}$ of tetraethylorthosilicate (TEOS) was diluted in $40 \mathrm{~mL}$ of isopropanol. After stirring, $50 \mathrm{~mL}$ of concentrated ammonium hydroxide were added and the dilute TEOS solution was added drop wise at a rate of $0.3 \mathrm{ml} / \mathrm{min}$. After the addition of the TEOS solution, the mixture was sonicated for another hour. Then the silica-coated magnetic nanoparticles (SiMNPs) were magnetically separated, washed four to five times with water and dried at $40^{\circ} \mathrm{C}$ in a forced air convection oven.

\subsection{Functionalization of SiMNPs}

Propyl-sulfonic (PS) acid grafting upon silica-coated nanoparticles was done using similar procedures to those used for functionalization of silicas [13,14,22-25]. About $500 \mathrm{mg}$ of dry SiMNPs and $1 \mathrm{ml}$ of MPTMS were sonicated in $100 \mathrm{ml}$ of ethanol for $1 \mathrm{~h}$. After sonication, 100 $\mathrm{ml}$ of $100 \mathrm{mM}$ acetate buffer at $\mathrm{pH} 4.8$ was added and the mixture was heated and mechanically stirred at $75^{\circ} \mathrm{C}$. After $16 \mathrm{~h}$ of reaction, the mercaptopropyl-functionalized nanoparticles were separated magnetically and washed three times with ethanol. Then, the nanoparticles were placed in a $60 \mathrm{ml}$ solution with equal amounts of water, methanol, and hydrogen peroxide for oxidization of the mercapto groups. After $48 \mathrm{~h}$ in the oxidizing solution, the nanoparticles were washed three times with distilled water and left overnight in $100 \mathrm{~mL}$ of $0.01 \mathrm{~N} \mathrm{HCl}$. After protonation, the PS nanoparticles were separated out of the acid solution and washed multiple times with distilled water. Then, the PS nanoparticles were dried at $120^{\circ} \mathrm{C}$ for $3 \mathrm{~h}$. 


\subsection{Characterization of the Nanoparticles}

Fourier transform infrared (FTIR) spectra were used to confirm the presence of the propyl-sulfonic acid bonds in the synthesized nanoparticles. The measurement was carried out in the wave number range of 500 to $4000 \mathrm{~cm}^{-1}$, with a resolution of $4 \mathrm{~cm}^{-1}$ and 32 scans per sample. The spectra and peak positions were determined using an infrared spectrometer and its spectrum software (Spectrum 400, PerkinElmer Inc., Waltham, Mass.).

Sulfur content was used as an indicator of the silane grafting level on the nanoparticles, and it was determined in an elemental analyzer (Model 2400 Series II, PerkinElmer Inc., Waltham, Mass.). The concentration of hydronium ions was calculated from the percentage of sulfur dividing by the molecular weight of the sulfur atom and the working volume.

\subsection{Pretreatment of Corn Stover}

Compositional analysis of the corn stover before pretreatment was done following the NREL LAP TP-510-42618 [26]. PS nanoparticles were used to pretreat corn stover and evaluate their ability to increase biomass susceptibility to enzymatic hydrolysis. A scheme of the steps followed to pretreat biomass using acid functionalized nanoparticles is shown in Figure 1. A Box-Behnken design was employed to calculate the minimum number experiments required to obtain an estimate of the surface response for temperature, catalyst load, and \%S content of the catalyst. A minimum of 17 experiments was calculated, and the results from 34 runs were analyzed using Design Expert (Stat-Ease, Inc., Minneapolis, Minn., USA). The pretreatment was carried out at 160,180 , and $200^{\circ} \mathrm{C}$. In a typical experiment, $0.1-0.3 \mathrm{~g}$ of PS nanoparticles, and $1.0 \mathrm{~g}$ of corn stover both weighted to the nearest $0.1 \mathrm{mg}$, and $39 \mathrm{ml}$ of distilled water were placed in $60 \mathrm{ml}$ Swagelok tube (Swagelok, Kansas City Valve \& Fitting Co., Kan.). Then, the tube was sonicated for 30 min to disperse the nanoparticles. After sonication, the tube was placed in a sand bath that was previously heated at the pretreatment temperature. After 60 min of reaction, the tube was cool down to room temperature in about 5 min. The control experiments had no catalyst and were carried out under the same conditions as the experiments using PS nanoparticles. After pretreatment, the solid and liquid fractions were separated via vacuum filtration using a Büchner funnel. The pretreated solids and the PS nanoparticles were retained in the paper filter and the solubilized sugars passed as filtrate. The solid material was washed with plenty of water to remove all the soluble sugars as described in [27]. Then, the solid fraction was hydrolyzed for $24 \mathrm{~h}$ following the NREL LAP TP510-42629 [28]. In a typical experiment, about $2.5 \mathrm{~g}$ of wet biomass were placed in $30 \mathrm{ml}$ of distilled water and

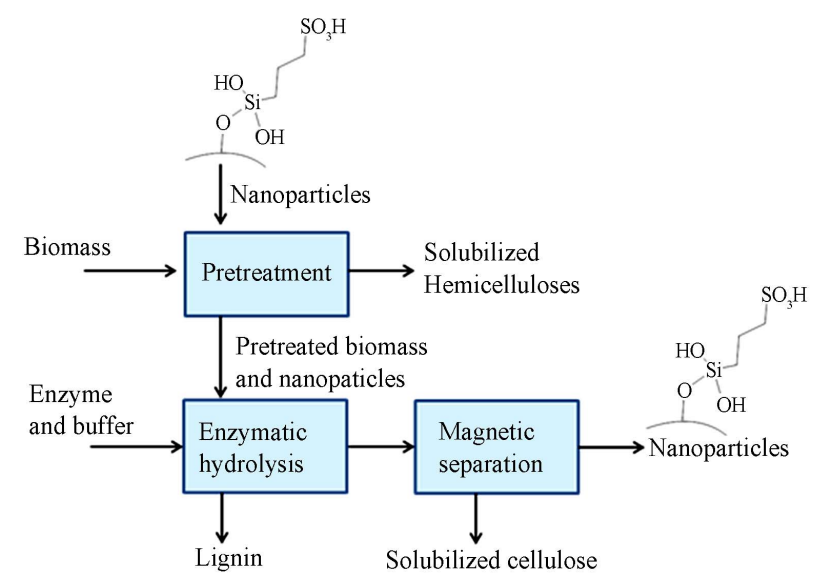

Figure 1. Schematic of the sugar recovery from corn stover using propyl-sulfonic acid functionalized nanoparticles during pretreatment.

$30 \mathrm{ml}$ of $100 \mathrm{mM}$ acetate buffer at $\mathrm{pH} 4.8$; after $2 \mathrm{ml}$ of Accelerase ${ }^{\circledR} 1500$ were added to the slurry, the samples were kept at $50^{\circ} \mathrm{C}$ for $24 \mathrm{~h}$. After hydrolysis, the solutions were analyzed by HPLC to account for glucose and xylose using a RCM-Ca ${ }^{2+}$ monosaccharide column (300 $\times 7.8 \mathrm{~mm}$; Phemomenex ${ }^{\circledR}$, Torrance, CA, USA) and refractive index detector. Samples were run at $80^{\circ} \mathrm{C}$ at 0.6 $\mathrm{ml} / \mathrm{min}$ with water as mobile phase. The PS nanoparticles were then separated from the enzymatically treated solution. A 400 mesh was used to retain the solid fraction left after enzymatic hydrolysis and then a magnet to wash the nanoparticles. The nanoparticles were then dried and analyzed by FTIR. The filtrate was passed over a filter membrane of $0.2 \mu \mathrm{m}$. The liquid fraction from the pretreatment was analyzed for sugars following NREL LAP TP-510-42623 [29]. The products of the decomposition of glucose and xylose, HMF, and furfural were measured using an ROA-organic acid column $(300 \times 7.8 \mathrm{~mm}$; Phemomenex ${ }^{\circledR}$, Torrance, CA) and an UV detector. Samples were run at $65^{\circ} \mathrm{C}$ at $0.6 \mathrm{ml} / \mathrm{min}$ with $5 \mathrm{mM} \mathrm{H}_{2} \mathrm{SO}_{4}$ for 55 min. The percentage of glucose converted to HMF was calculated multiplying the concentration of HMF by 1.429. The percentage of xylose converted to furfural was calculated multiplying the concentration of furfural by 1.562 .

\subsection{Recyclability Experiments}

The stability of the PS nanoparticles was evaluated using cellobiose hydrolysis as model reaction of biomass pretreatment. Solutions of $4 \mathrm{mg} / \mathrm{ml}$ of cellobiose and 1\% PS nanoparticles were placed in a $60 \mathrm{ml}$ Swagelok tubes (Swagelok, Kansas City Valve \& Fitting Co., Kan.). The tubes were kept at $175^{\circ} \mathrm{C}$ for $30 \mathrm{~min}$ in a sand bath. The sugar solution and the PS nanoparticles were separated using a neodymium magnet and dried at $105^{\circ} \mathrm{C}$. PS nanoparticles were analyzed with the elemental analyzer as 
described above.

\section{Results and Discussion}

FTIR spectra taken to the acid-functionalized nanoparticles are shown in Figure 2. The peaks at $1620 \mathrm{~cm}^{-1}$ and $3400 \mathrm{~cm}^{-1}$ observed on the spectra have been attributed to the $\mathrm{O}-\mathrm{H}$ vibration and stretching vibrations of physisorbed water. These bands could also be associated to silanol groups of the SiMNPs [30,31] that did not reacted with MPTMS. It has been reported that only one hydroxyl group from silanols attaches to silica surfaces [32]. Therefore, the hydroxyl groups of the propylsilanol moieties can also generate bands at $3400 \mathrm{~cm}^{-1}$. The peaks at $1950-1929 \mathrm{~cm}^{-1}$ are associated with symmetric and asymmetric vibrations of the $\mathrm{C}-\mathrm{H}$ bonds in the propyl chain, respectively [30,33,34]. Deformation vibrations bands of $-\mathrm{CH}_{2}$ are also observed at $1457 \mathrm{~cm}^{-1}$ [35]. In the fingerprint region, we can observe the bands attributed to Si-O-Si, Si-OH, and Si-O at 1078, 956, $800 \mathrm{~cm}^{-1}[33,36-$ 38]. The peaks at $1414 \mathrm{~cm}^{-1}$ in the spectra for PS nanoparticles have been assigned to the stretching vibrations of $\mathrm{S}=\mathrm{O}$ from undissociated acid sulfonic groups $[39,40]$. The doublet at 1350 and $1310 \mathrm{~cm}^{-1}$ has been attributed to stretching vibrations of $-\mathrm{SO}_{3}$-species [40]. The peak at $2520 \mathrm{~cm}^{-1}$ [41] associated to thiol groups from the mercaptopropyl groups was not observed. This means that all the groups were either oxidized to sulfonic acid groups or to other $\mathrm{S}$ species. Other authors have found evidence of the formation of S-S bridges when working with MPTMS; however, bands associated with S-S were not observed either. The bands at 743 and $691 \mathrm{~cm}^{-1}$ may be attributed to S-OR species.

The sulfur content \%S of PS nanoparticles varied from $5.01 \%$ to $9.94 \%$. Badley et al. (1989) reported values of \%S between $3.25 \%$ and $8.32 \%$ for propyl-sulfonic acid

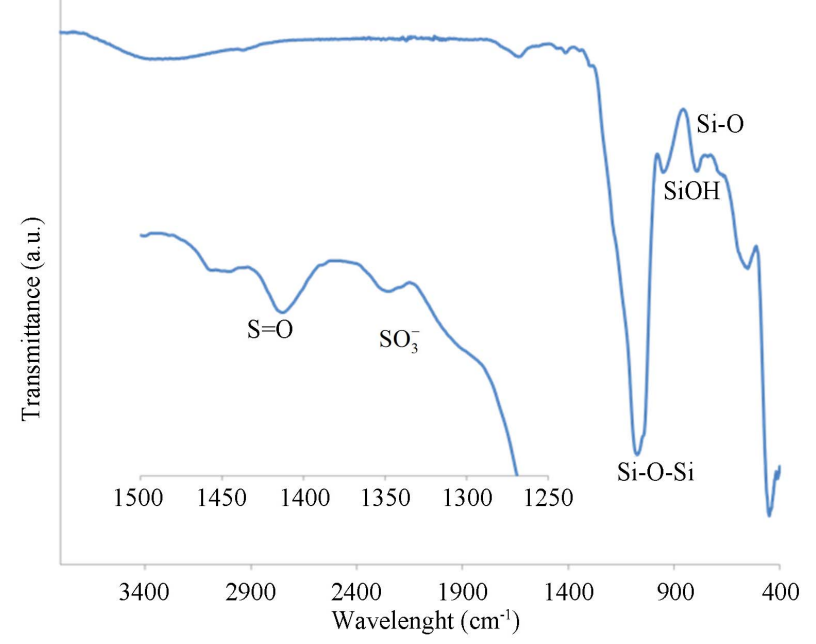

Figure 2. FT-IR spectra of propyl-sulfonic acid functionalized nanoparticles. functionalized silicas [25]. Other works reported 1.17 meq S/g (3.7\%) for propyl-sulfonic modified SBA-15 [42] and 10.88 S\% on thiol-MCM-41 [43]. However, it is possible that not all the sulfur was in the sulfonic acid form even though there wasn't evidence of S-S bridged or non-oxidized -SH groups in the FTIR spectra [24].

Predicted total glucose yield from corn stover is shown in Figure 3. The red dots indicate design points, and the lines represent the modeled glucose yield as a function of pretreatment temperature and catalyst loading. At $160^{\circ} \mathrm{C}$, PS nanoparticles did not show a significant improvement in the digestibility of the biomass. The average glucose yield obtained at this temperature was 59.02\% $( \pm 5.48)$ out of 11 experiments that use various catalyst load levels. Even though PS nanoparticles were effectively modified $(5 \%-9 \% \mathrm{~S})$ at $160^{\circ} \mathrm{C}$ the sugar yield was very close to that of the hydro-thermolysis (0 $\mathrm{mg} \mathrm{S} / \mathrm{g}$ biomass). Aggregation of the particles could have caused limited availability of catalytic sites for reaction with the carbohydrate-lignin bonds in biomass. On the other hand, at $200^{\circ} \mathrm{C}$ complete sugar hydrolysis occurred, so it was not possible to tell the differences between the control experiments and the performance of the catalyst. At $200^{\circ} \mathrm{C}$, the xylose recovery was less than $6 \%$. This can be explained also by the fact that high temperatures catalyze the production of xylose derived products [44]. A maximum yield of xylose could be reached with a catalyst load of $6 \mathrm{mg} \mathrm{S} / \mathrm{g}$ biomass between $165^{\circ} \mathrm{C}$ and $175^{\circ} \mathrm{C}$ (Figure 4). At low temperatures, a load of catalyst higher than $30 \mathrm{mg} / \mathrm{g}$ biomass, which is equivalent to using 24 $\mathrm{mmol} \mathrm{H} / \mathrm{L}$, would be required in order to increase the xylose yield over $50 \%$. Xylose yield increases along with the temperature; however, after $175^{\circ} \mathrm{C}$ the xylose yield decrease rapidly because at these temperatures the sugars can be degraded to other products such as furfural and formic acid [44]. Some works have been reported about the use of supported acids to produce carbohydrate derived products such as HMF and furfural $[45,46]$. The amount of glucose that was lost as HMF is shown in Figure 5. The HMF formation increased along with catalyst load and temperature. At $160^{\circ} \mathrm{C}$ the amount of glucose lost was less than $2 \%$ for all catalyst loadings tested. At $200^{\circ} \mathrm{C}$, about $11 \%$ of the total glucose in the corn stover samples was lost at the higher catalyst load. The amount of xylose lost as furfural is shown in Figure 6. The amount of xylose lost because of furfural formation increased along with temperature. At $160^{\circ} \mathrm{C}$, xylose degradation was close to zero, and at $200^{\circ} \mathrm{C}$ the amount of xylose lost as furfural reached $30 \%$.

With catalyst loadings up to $30 \mathrm{mg}$ S/g biomass, a temperature of $160^{\circ} \mathrm{C}$ did not provide an effective catalysis of the corn stover pretreatment. At $200^{\circ} \mathrm{C}$, the hemicellulose sugars were thermally degraded. Therefore the 


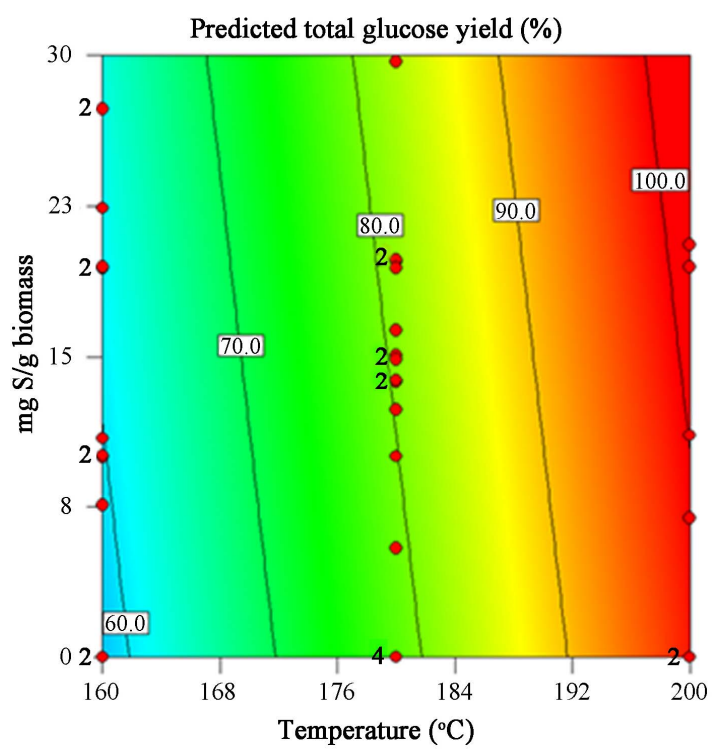

Figure 3. Contour graph of the model for total glucose yield from corn stover as a function of pretreatment temperature and catalyst loading.

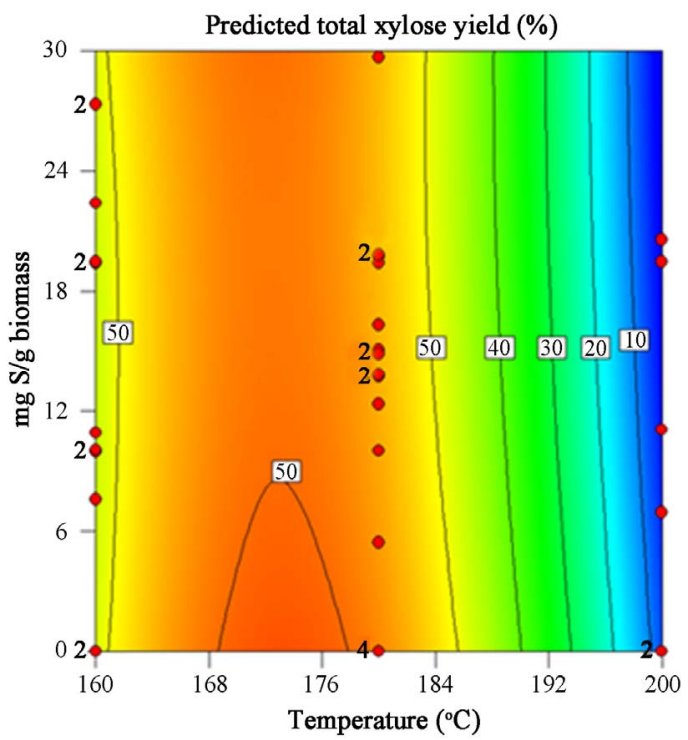

Figure 4. Contour graph of the model for total xylose yield as function of pretreatment temperature and catalyst loading.

set of experiments carried out at a temperature of $180^{\circ} \mathrm{C}$, were used for statistical analysis. A Bonferroni correction was applied for which a $P$-value of 0.025 was used as criteria for significance for this set. At $180^{\circ} \mathrm{C}$, the total glucose yield was linearly correlated to the load of catalyst which was indicated in terms of total sulfur mass (Figure 7). A maximum glucose yield of 90\% was reached when using $0.2 \mathrm{~g}$ of PS nanoparticles that had a total sulfur content of $6.1 \%$.

PS nanoparticles could have been done a better job pretreating corn stover if they did not aggregate and form

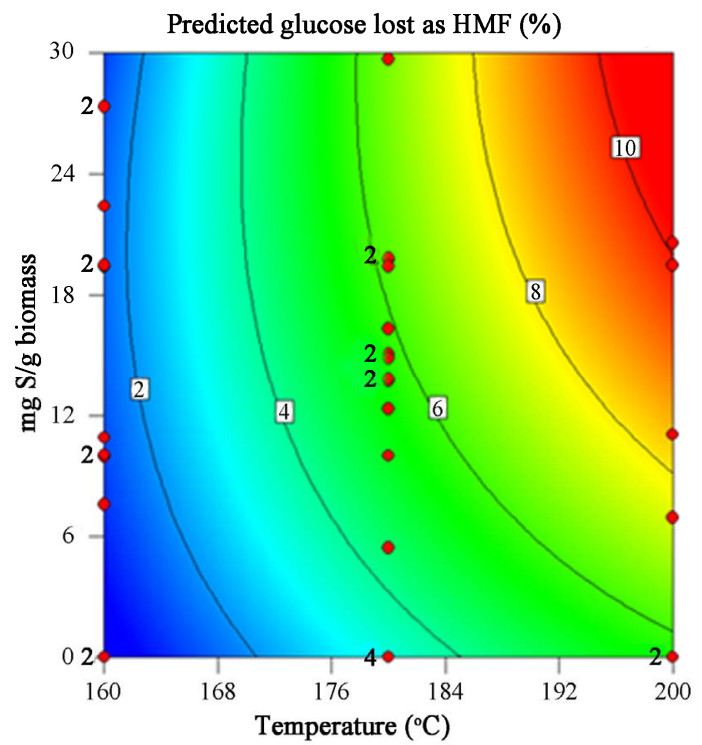

Figure 5. Contour graph of the model for the percentage of glucose lost as HMF as a function of pretreatment temperature and catalyst loading.

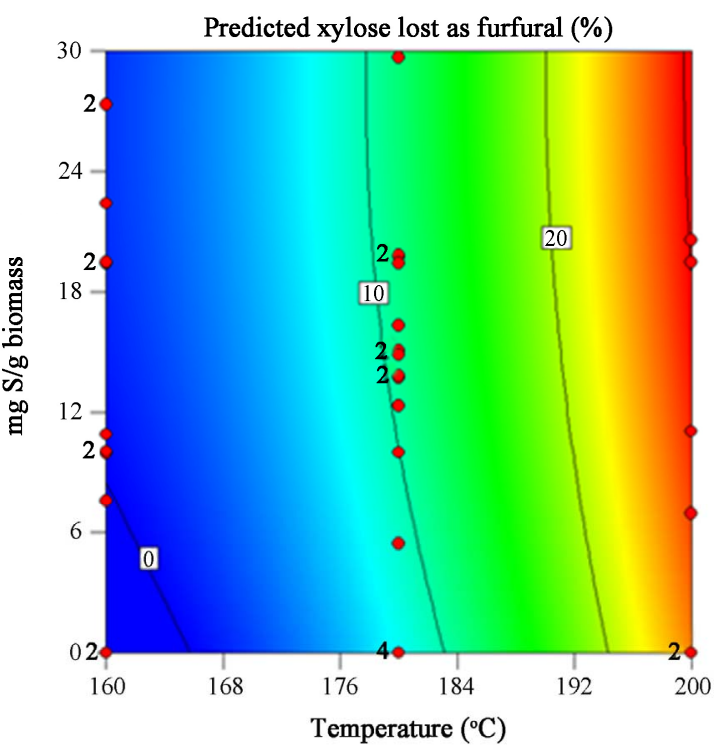

Figure 6. Contour graph of the model for the percentage of xylose lost as furfural as a function of pretreatment temperature and catalyst loading.

clumps. Aggregation of the nanoparticles hides the catalytic sites and makes them unavailable for reaction. It is also possible that sulfate salts were formed with the ions derived from trace minerals in biomass. PS nanoparticles seemed to have affinity towards pretreated biomass since it was very difficult to remove biomass entirely in order to analyze the nanoparticles after pretreatment. This was evidenced by the increment in carbon content in the PS nanoparticles after pretreatment (Table 2). Even though the nanoparticles were present during the enzymatic hydrolysis, inhibitory character of acid-functionalized na- 
Table 2. Elemental analysis of PS nanoparticles before and after cellobiose hydrolysis at $175^{\circ} \mathrm{C}$.

\begin{tabular}{ccccc}
\hline PS nanoparticle & $\% \mathrm{C}$ & $\% \mathrm{H}$ & $\% \mathrm{~N}$ & $\% \mathrm{~S}$ \\
\hline Before cellobiose hydrolysis & 11.86 & 2.39 & - & 9.81 \\
After cellobiose hydrolysis & 11.10 & 2.33 & - & 9.00 \\
Before corn stover pretreatment & 11.43 & 2.62 & - & 9.59 \\
After corn stover pretreatment & 24.67 & 3.32 & 2.21 & 3.13 \\
\hline
\end{tabular}

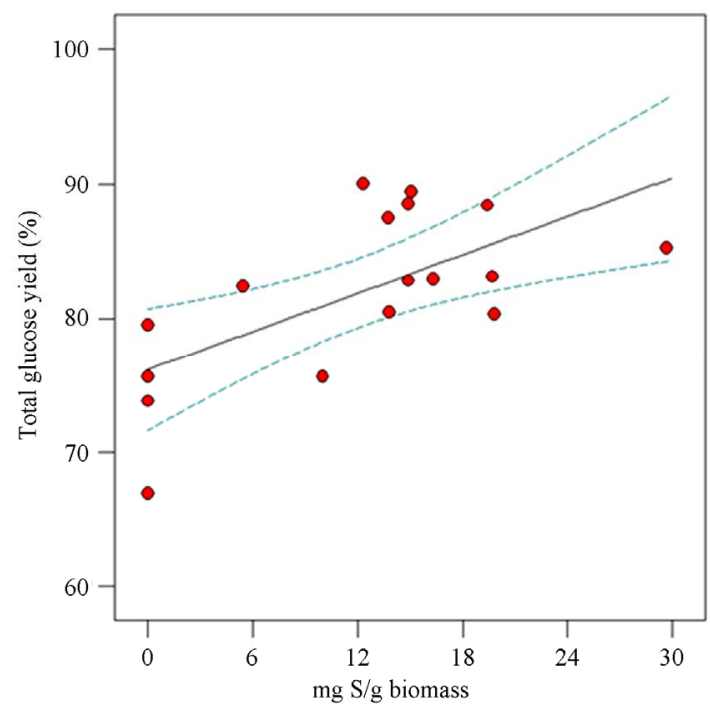

Figure 7. Total glucose yield from corn stover as a function of catalyst loading at $180^{\circ} \mathrm{C}$ for one hour.

noparticles was not observed. Since complete glucose recovery was reached for some of the experiments we believe that PS nanoparticles did not block the access of the enzyme to the carbohydrate fraction.

Hydrolysis of cellobiose has been used as model reaction of the hydrolysis of cellulose into its constituent glucose units $[16,47,48]$. In this work, we used the same reaction to analyze the stability of the propyl-sulfonic acid groups in PS nanoparticles. To assess the loss of functional groups during reaction, the sulfur content of the nanoparticles was measured before and after cellobiose hydrolysis (Table 2). The PS nanoparticles lost about $1 \%$ of their sulfonic acid groups after hydrolysis of cellobiose at $175^{\circ} \mathrm{C}$ which is an indicator that PS nanoparticles kept most of their functional groups, and that these groups are stable during catalysis in aqueous media reactions at high temperatures. Elemental analysis was also done upon PS nanoparticles after pretreatment. However, it was difficult to separate material left after pretreatment entirely. Because the organic content of the nanoparticles increased and it was difficult to determine the real percentage of sulfonic groups after pretreatment. An FTIR spectrum was also taken after pretreatment with PS nanoparticles (Figure 8). The band at $1510 \mathrm{~cm}^{-1}$, characte-

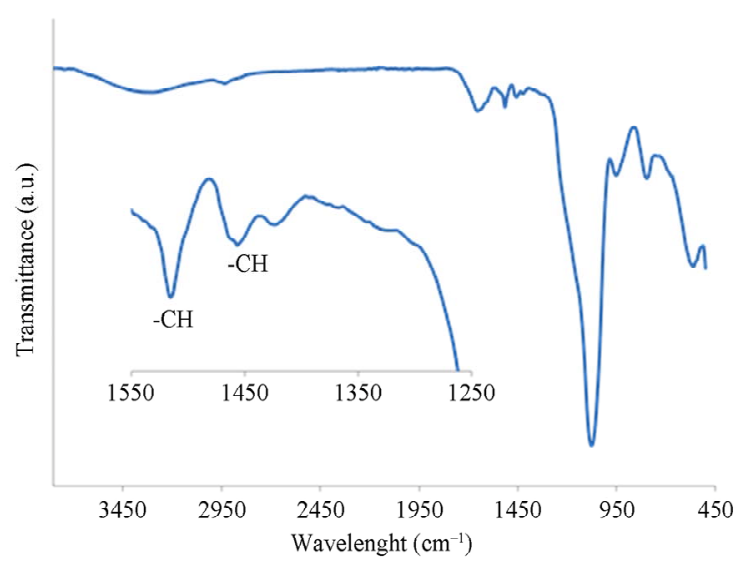

Figure 8. FTIR spectra of PS nanoparticles after pretreatment of corn stover at $180^{\circ} \mathrm{C}$ for $1 \mathrm{~h}$.

ristic of lignin, [49] was observed, as well as an increment in the intensity of the band at $1457 \mathrm{~cm}^{-1}$ associated to $\mathrm{C}-\mathrm{H}$ bonds. Although, the absorption of material, it is not a desired condition; it can be an indicator of the affinity of these nanoparticles towards cellulose derived materials, which it is necessary to carry out catalysis effectively.

\section{Conclusion}

A maximum glucose yield of $90 \%$ was reached when using $0.2 \mathrm{~g}$ of PS nanoparticles that had a total sulfur content of $6.1 \%$. The average glucose yield was linearly correlated to the load of PS nanoparticles at $180^{\circ} \mathrm{C}$. At $160^{\circ} \mathrm{C}$, the amount of PS nanoparticles required to increase the glucose yield above the one obtained without catalyst must be higher than $30 \mathrm{mg} \mathrm{S} / \mathrm{g}$ biomass which will be equivalent to using $24 \mathrm{mmol} \mathrm{H}^{+} / \mathrm{L}$. At $200^{\circ} \mathrm{C}$, complete cellulose hydrolysis to glucose was achieved but $96 \%$ of corn stover hemicelluloses were lost as degradation products. PS nanoparticles kept $99 \%$ of their propyl-sulfonic acid load after hydrolysis of cellobiose at $175^{\circ} \mathrm{C}$.

\section{Acknowledgements}

This research was funded by NSF EPSCoR Kansas Center for Solar Energy Research and facilitated by Kansas State University. This material also is based upon work supported by National Science Foundation Grant: From Crops to Commuting: Integrating the Social, Technological, and Agricultural Aspects of Renewable and Sustainable Biorefining (I-STAR); NSF Award No.: DGE-0903701.

\section{REFERENCES}

[1] V. Chang and M. Holtzapple, "Fundamental Factors Affecting Biomass Enzymatic Reactivity,” Applied Biochemistry and Biotechnology, Vol. 84-86, No. 1-9, 2000, pp. 
5-37.

[2] G. Gonzalez, J. LopezSantin, G. Caminal and C. Sola, "Dilute Acid-Hydrolysis of Wheat Straw Hemicellulose at Moderate Temperature-A Simplified Kinetic-Model," Biotechnology and Bioengineering, Vol. 28, No. 2, 1986, pp. 288-293. http://dx.doi.org/10.1002/bit.260280219

[3] A. Herrera, S. J. Tellez-Luis, J. J. Gonzalez-Cabriales, J. A. Ramirez and M. Vazquez, "Effect of the Hydrochloric Acid Concentration on the Hydrolysis of Sorghum Straw at Atmospheric Pressure," Journal of Food Engineering, Vol. 63, No. 1, 2004, p. 103. http://dx.doi.org/10.1016/S0260-8774(03)00288-7

[4] Y. Lee and S. Kim, "Diffusion of Sulfuric Acid within Lignocellulosic Biomass Particles and Its Impact on Dilute-Acid Pretreatment,” Bioresource Technology, Vol. 83, No. 2, 2002, pp. 165-171. http://dx.doi.org/10.1016/S0960-8524(01)00197-3

[5] E. Viola, F. Nanna, E. Larocca, M. Cardinale, D. Barisano and F. Zimbardi, "Acid Impregnation and Steam Explosion of Corn Stover in Batch Processes,” Industrial Crops and Products, Vol. 26, No. 2, 2007, p. 195. http://dx.doi.org/10.1016/j.indcrop.2007.03.005

[6] C. E. Wyman, B. E. Dale, R. T. Elander, M. Holtzapple, M. R. Ladisch and Y. Y. Lee, "Coordinated Development of Leading Biomass Pretreatment Technologies," Bioresource Technology, Vol. 96, No. 18, 2005, pp. 1959-1966. http://dx.doi.org/10.1016/j.biortech.2005.01.010

[7] J. Delgenes, "Effects of Lignocellulose Degradation Products on Ethanol Fermentations of Glucose and Xylose by Saccharomyces Cerevisiae, Zymomonas Mobilis, Pichia Stipitis, and Candida Shehatae,” Enzyme and Microbial Technology, Vol. 19, No. 3, 1996, pp. 220-225. http://dx.doi.org/10.1016/0141-0229(95)00237-5

[8] G. D. Yadav, "Synergism of Clay and Heteropoly Acids as Nano-Catalysts for the Development of Green Processes with Potential Industrial Applications,” Catalysis Surveys from Asia, Vol. 9, No. 2, 2005, pp. 117-137.

[9] S. Chafin, K. Pennybaker, D. Fahey, B. Subramaniam and K. Gong, "Economic and Environmental Impact Analyses of Solid Acid Catalyzed Isoparaffin/Olefin Alkylation in Supercritical Carbon Dioxide," Industrial Engineering Chemistry Research, Vol. 47, No. 23, 2008, p. 9072. http://dx.doi.org/10.1021/ie800399s

[10] M. A. Harmer, C. Junk, V. Rostovtsev, L. G. Carcani, J. Vickery and Z. Schnepp, "Synthesis and Applications of Superacids. 1,1,2,2-Tetrafluoroethanesulfonic Acid, Supported on Silica,” Green Chemistry, Vol. 9, No. 1, 2007, pp. 30. http://dx.doi.org/10.1039/b607428f

[11] M. A. Harmer, W. E. Farneth and Q. Sun, "Towards the Sulfuric Acid of Solids," Advanced Materials, Vol. 10, No. 15, 1998, p. 1255. http://dx.doi.org/10.1002/(SICI)1521-4095(199810)10:15 $<$ 1255::AID-ADMA1255>3.0.CO;2-T

[12] R. Raja and J. M. Thomas, "The Expanding World of Nanoparticle and Nanoporous Catalysts,” In: P. Yang, Ed., The Chemistry of Nanostructured Materials, World Scien- tific Publishing Co. Pte. Ltd., Singapore City, 2003, pp. 329-357. http://dx.doi.org/10.1142/9789812560049_0012

[13] C. S. Gill, B. A. Price and C. W. Jones, "Sulfonic Acid-
Functionalized Silica-Coated Magnetic Nanoparticle Catalysts," Journal of Catalysis, Vol. 251, No. 1, 2007, pp. 145-152. http://dx.doi.org/10.1016/j.jcat.2007.07.007

[14] P. F. Siril, A. D. Davison, J. K. Randhawa and D. R. Brown, "Acid Strengths and Catalytic Activities of Sulfonic Acid on Polymeric and Silica Supports," Journal of Molecular Catalysis A: Chemical, Vol. 267, No. 1-2, 2007, p. 72. http://dx.doi.org/10.1016/j.molcata.2006.11.022

[15] P. L. Dhepe, M. Ohashi, S. Inagaki, M. Ichikawa and A. Fukuoka, "Hydrolysis of Sugars Catalyzed by Water-Tolerant Sulfonated Mesoporous Silicas," Catalysis Letters, Vol. 102, No. 3-4, 2005, p. 163. http://dx.doi.org/10.1007/s10562-005-5850-x

[16] J. A. Bootsma and B. H. Shanks, "Cellobiose Hydrolysis Using Organic-Inorganic Hybrid Mesoporous Silica Catalysts," Applied Catalysis A-General, Vol. 327, No. 1, 2007, pp. 44-51. http://dx.doi.org/10.1016/j.apcata.2007.03.039

[17] L. Peña, M. Ikenberry, B. Ware, K. L. Hohn, D. Boyle and D. Wang, "Cellobiose Hydrolysis Using Acid-Functionalized Nanoparticles," Biotechnology and Bioprocess Engineering, Vol. 16, No. 6, 2011, pp. 1214-1222. http://dx.doi.org/10.1007/s12257-011-0166-8

[18] L. Peña, M. Ikenberry, K. L. Hohn and D. Wang, “AcidFunctionalized Nanoparticles for Pretreatment of Wheat Straw," Journal of Biomaterials and Nanobiotechnology, Vol. 3, No. 3, 2012, pp. 342-352. http://dx.doi.org/10.4236/jbnb.2012.33032

[19] A. J. Rondinone, A. C. S. Samia and Z. J. Zhang, "Superparamagnetic Relaxation and Magnetic Anisotropy Energy Distribution in $\mathrm{CoFe}_{2} \mathrm{O}_{4}$ Spinel Ferrite Nanocrystallites," Journal of Physical Chemistry B, Vol. 103, No. 33, 1999, pp. 6876-6880. http://dx.doi.org/10.1021/jp9912307

[20] N. Moumen, P. Bonville and M. Pileni, "Control of the Size of Cobalt Ferrite Magnetic Fluids: Mossbauer Spectroscopy," Journal of Physical Chemistry, Vol. 100, No. 34, 1996, pp. 14410-14416. http://dx.doi.org/10.1021/jp953324w

[21] X. Shen, X. Fang, Y. Zhou and H. Liang, "Synthesis and Characterization of 3-Aminopropyltriethoxysilane-Modified Superparamagnetic Magnetite Nanoparticles," Chemistry Letters, Vol. 33, No. 11, 2004, pp. 1468-1469. http://dx.doi.org/10.1246/cl.2004.1468

[22] G. Morales, G. Athens, B. Chmelka, R. van Grieken and J. Melero, "Aqueous-Sensitive Reaction Sites in Sulfonic Acid-Functionalized Mesoporous Silicas,” Journal of Catalysis, Vol. 254, No. 2, 2008, pp. 205-217. http://dx.doi.org/10.1016/j.jcat.2007.12.011

[23] S. Hamoudi, S. Royer and S. Kaliaguine, "Propyl- and Arene-Sulfonic Acid Functionalized Periodic Mesoporous Organosilicas,” Microporous and Mesoporous Materials, Vol. 71, No. 1-3, 2004, pp. 17-25. http://dx.doi.org/10.1016/j.micromeso.2004.03.009

[24] E. Cano Serrano, J. Campos Martin and J. Fierro, "Sulfonic Acid-Functionalized Silica through Quantitative Oxidation of Thiol Groups," Chemical Communications (London, 1996), Vol. 39, No. 2, 2003, pp. 246-247. 
[25] R. Badley and W. Ford, "Silica-Bound Sulfonic-Acid Catalysts,” Journal of Organic Chemistry, Vol. 54, No. 23, 1989, pp. 5437-5443. http://dx.doi.org/10.1021/jo00284a014

[26] A. Sluiter, B. Hames, R. Ruiz, et al., "Determination of Structural Carbohydrates and Lignin in Biomass,” NREL/ TP-510-42618, National Renewable Energy Laboratory, Golden, 2008.

[27] A. Sluiter, D. Hyman, C. Payne and J. Wolfe, "Determination of Insoluble Solids in Pretreated Biomass Material,” NREL/TP-510-42618, National Renewable Energy Laboratory, Golden, 2008.

[28] M. Selig, N. Weiss and Y. Ji, "Enzymatic Saccharification of Lignocellulosic Biomass,” NREL/ TP-510-42618, National Renewable Energy Laboratory, Golden, 2008.

[29] A. Sluiter, B. Hames, R. Ruiz, C. Scarlata, J. Sluiter and D. Templeton, "Determination of Sugars, Byproducts, and Degradation Products in Liquid Fraction Process Samples,” NREL/ TP-510-42618, National Renewable Energy Laboratory, Golden, 2008.

[30] D. Brunel, A. Cauvel, F. Di Renzo, F. Fajula and B. Fubini, "Preferential Grafting of Alkoxysilane Coupling Agents on the Hydrophobic Portion of the Surface of Micelle-Templated Silica,” New Journal of Chemistry, Vol. 24, No. 10, 2000, pp. 807-813. http://dx.doi.org/10.1039/b002945i

[31] M. Hair, "Hydroxyl-Groups on Silica Surface,” Journal of Non-Crystalline Solids, Vol. 19, 1975, pp. 299-309. http://dx.doi.org/10.1016/0022-3093(75)90095-2

[32] U. H. Goerl, A. Mueller and H. G. Arndt Koban, "Investigations into the Silica/Silane Reaction System," Rubber Chemistry and Technology, Vol. 70, No. 4, 1997, pp. 608623. http://dx.doi.org/10.5254/1.3538447

[33] M. Colilla, I. Izquierdo-Barba, S. Sanchez-Salcedo, J. Fierro, J. Hueso and M. Vallet-Regi, "Synthesis and Characterization of Zwitterionic SBA-15 Nanostructured Materials," Chemistry of Materials, Vol. 22, No. 23, 2010, pp. 6459-6466. http://dx.doi.org/10.1021/cm102827y

[34] L. Dubois and B. Zegarski, "Bonding of Alkoxysilanes to Dehydroxylated Silica Surfaces-A New Adhesion Mechanism,” Journal of Physical Chemistry, Vol. 97, No. 8, 1993, pp. 1665-1670. http://dx.doi.org/10.1021/j100110a032

[35] B. Rac, A. Molnar, P. Forgo, M. Mohai and I. Bertoti, “A Comparative Study of Solid Sulfonic Acid Catalysts Based on various Ordered Mesoporous Silica Materials," Journal of Molecular Catalysis. A, Chemical, Vol. 244, No. 1-2, 2006, p. 46. http://dx.doi.org/10.1016/j.molcata.2005.08.043

[36] X. S. Zhao, G. Q. Lu and X. Hu, "Characterization of the Structural and Surface Properties of Chemically Modified MCM-41 Material," Microporous and Mesoporous Materials, Vol. 41, No. 1-3, 2000, pp. 37-47.

[37] C. Tripp and M. Hair, "Reaction of Methylsilanols with Hydrated Silica Surfaces-The Hydrolysis of Trichloromethylsilanes, Dichloromethylsilanes, and Monochloromethylsilanes and the Effects of Curing," Langmuir, Vol. 11, No. 1, 1995, pp. 149-155. http://dx.doi.org/10.1021/la00001a027

[38] A. L. Smith, "Infrared Spectra-Structure Correlations for Organosilicon Compounds,” Spectrochimica Acta, Vol. 16, No. 1-2, 1960, pp. 87-105. http://dx.doi.org/10.1016/0371-1951(60)80074-4

[39] M. Alvaro, A. Corma, D. Das, V. Fornes and H. Garcia, “'Nafion'-Functionalized Mesoporous MCM-41 Silica Shows High Activity and Selectivity for Carboxylic Acid Esterification and Friedel-Crafts Acylation Reactions," Journal of Catalysis, Vol. 231, No. 1, 2005, p. 48. http://dx.doi.org/10.1016/j.jcat.2005.01.007

[40] R. Buzzoni, S. Bordiga, G. Ricchiardi, G. Spoto and A. Zecchina, "Interaction of $\mathrm{H}_{2} \mathrm{O}, \mathrm{CH}_{3} \mathrm{OH},\left(\mathrm{CH}_{3}\right)_{2} \mathrm{O}, \mathrm{CH}_{3} \mathrm{CN}$, and Pyridine with the Superacid Perfluorosulfonic Membrane Nafion: An IR and Raman Study,” Journal of Physical Chemistry, Vol. 99, No. 31, 1995, pp. 11937-11951. http://dx.doi.org/10.1021/j100031a023

[41] I. Diaz, C. Marquez-Alvarez, F. Mohino, J. Perez-Pariente and E. Sastre, "Combined Alkyl and Sulfonic Acid Functionalization of MCM-41-Type Silica Part 1. Synthesis and Characterization," Journal of Catalysis, Vol. 193, No. 2, 2000, pp. 283-294. http://dx.doi.org/10.1006/jcat.2000.2898

[42] J. Melero, L. Fernando Bautista, G. Morales, J. Iglesias and R. Sanchez Vazquez, "Biodiesel Production from Crude Palm Oil Using Sulfonic Acid-Modified Mesostructured Catalysts," Chemical Engineering Journal, Vol. 161, No. 3, 2010, pp. 323-331. http://dx.doi.org/10.1016/j.cej.2009.12.037

[43] M. Lim, C. Blanford and A. Stein, "Synthesis of Ordered Microporous Silicates with Organosulfur Surface Groups and Their Applications as Solid Acid Catalysts," Chemistry of Materials, Vol. 10, No. 2, 1998, p. 467. http://dx.doi.org/10.1021/cm970713p

[44] O. Bobleter, "Hydrothermal Degradation of Polymers Derived from Plants,” Progress in Polymer Science, Vol. 19, No. 5, 1994, pp. 797-841. http://dx.doi.org/10.1016/0079-6700(94)90033-7

[45] V. V. Ordomsky, J. van der Schaaf, J. C. Schouten, T. A. Nijhuis, "Fructose Dehydration to 5-Hydroxymethylfurfural over Solid Acid Catalysts in a Biphasic System," ChemSusChem, Vol. 5, No. 9, 2012, pp. 1812-1819. http://dx.doi.org/10.1002/cssc.201200072

[46] C. Moreau, R. Durand, D. Peyron, J. Duhamet, P. Rivalier, "Selective Preparation of Furfural from Xylose over Microporous Solid Acid Catalysts," Industrial Crops and Products, Vol. 7, No. 2-3, 1998, pp. 95-99. http://dx.doi.org/10.1016/S0926-6690(97)00037-X

[47] D. Lai, L. Deng, Q. Guo and Y. Fu, "Hydrolysis of Biomass by Magnetic Solid Acid," Energy Environmental Science, Vol. 4, No. 9, 2011, pp. 3552-3557.

[48] K. Shimizu, H. Furukawa, N. Kobayashi, Y. Itaya and A. Satsuma, "Effects of Bronsted and Lewis Acidities on Activity and Selectivity of Heteropolyacid-Based Catalysts for Hydrolysis of Cellobiose and Cellulose," Green Chemistry, Vol. 11, No. 10, 2009, pp. 1627-1632. http://dx.doi.org/10.1039/b913737h

[49] R. Gosselink, J. van Dam, C. Boeriu and D. Bravo, “Cha- 
racterisation of Structure-Dependent Functional Properties of Lignin with Infrared Spectroscopy,” Industrial
Crops and Products, Vol. 20, No. 2, 2004, pp. 205-218. http://dx.doi.org/10.1016/j.indcrop.2004.04.022 